\title{
O Novo Modelo de Gestão e a Democratização e Participação na Escola:
}

\section{perspetivas de atores educativos}

\section{The New Management Model and the Democratization and Participation in the School: perspectives of educational agents}

\author{
Fernanda Martins, Ana Paula Macedo \\ Universidade do Minho
}

\begin{abstract}
Resumo
O presente trabalho insere-se numa investigação mais ampla sobre $A$ governação e gestão das escolas públicas: $o$ (a) diretor(a) em ação, sendo um dos seus eixos de análise a introdução da Nova Gestão Pública nas organizações escolares. Neste âmbito, realizamos o estudo de caso de uma escola do ensino secundário. Foram realizadas entrevistas aos atores educativos pertencentes aos diferentes órgãos de gestão em torno da implementação do novo modelo de gestão. Os dados recolhidos permitem-nos conhecer e problematizar a receção e recontextualização do referido modelo, sendo aqui de destacar a relação entre o diretor e o conselho geral e os sentidos de colegialidade na gestão.

Palavras-chave: gestão escolar, democracia, formação de profesores
\end{abstract}

\begin{abstract}
This work is part of a broader investigation on The governance and management of the public schools: the director in action, as one of its axis of analysis the introduction of the New Public Management in the educational organizations. Within this scope, we have realized the case study of a school of the secondary education. We have realized interviews to the educational agents of different management bodies, on the implementation of the new management model. The collected data allow us to know and question the reception and recontextualization of that model, highlighting the relation between the director and the general council, and the meanings of the collegiality in management.

Key-words: school management, democracy, training of teachers
\end{abstract}

\section{Um novo modelo para a gestão das escolas públicas portuguesas}

O Decreto-Lei $\mathrm{n}^{\mathrm{o}} 75 / 2008$, de 22 de abril tem sido objeto de múltiplas investigações com um pressuposto comum que assenta, por um lado, no carácter recentralizador do poder político e da administração escolar e, por outro lado, pela emergência da liderança unipessoal concentrando sobre si vários poderes e competências. Importa contextualizar que esta última alteração surge em decorrência de um processo lento e gradual de concentração de poderes no órgão de gestão, ainda que em períodos e em modelos anteriores o órgão de gestão apresentasse uma configuração colegial (cf. Martins, 2009; 2011). Também importa clarificar que esta alteração ao modelo de gestão ocorre no contexto de implementação de um outro conjunto de medidas em matéria de administração escolar, destacando-se: a constituição de agrupamentos de escolas, a adesão a modalidades de autonomia técnica e instrumental, entre outras.

Dentro deste cenário surgem interpretações acerca da figura do diretor que se inscrevem num movimento de desconcentração algo radicalizado, capaz de assegurar o tradicional predomínio do centro sobre as periferias e de o dotar de maior eficácia em termos de controlo, transformando o seu cargo no "rosto" do poder central junto da escola.

Note-se que a expressão desta nova lógica de regulação das escolas era previsível, uma vez que desde a década de 1980 já existiam sinais de mudanças - práticas de gestão democrática débeis, consubstanciadas, entre outros aspetos num decréscimo substantivo na apresentação de listas concorrentes ao conselho diretivo (Lima, 2011). Assim, assiste-se à imposição de um novo modelo de governação que, para além da concentração de poderes no órgão de gestão, acaba por atribuir significativos poderes e competências a um único sujeito, "dessa forma alongando e verticalizando o respetivo organigrama e reforçando as prerrogativas de uma liderança formalmente unipessoal” (Lima, 2011, p. 47). De modo específico,

“(...) o director concentra sobre si vinte e cinco competências, preside ao conselho pedagógico por inerência, tudo parecendo girar em seu torno, fragilizando as estruturas colegiais existentes e pondo fim à quase totalidade dos processos de escolha democrática nas escolas (...). O director passa, agora, a nomear e a demitir livremente o subdirector, os assessores, os coordenadores de departamentos, os coordenadores dos estabelecimentos agrupados, numa lógica gestionária de um perfil, um projeto, uma equipa de gestão, remetendo para algo semelhante ao princípio da 'unidade de comando', proposto no início do seculo XX por Henri Fayol (1984)" (ídem, p.58).

A centralidade remetida ao diretor, responsável por cada escola ou agrupamento pode ser um factor de erosão da gestão democrática e, consequentemente, de fragmentação das práticas de colegialidade dos 
profissionais, que cada vez se vão tornando mais formais e uniformes. Para além deste plano de funcionamento da organização regista-se, no que diz respeito à supervisão da execução das políticas educativas centrais, a existência de uma ambiguidade latente na figura do diretor, a tradução normativa e estrutural do Decreto-lei $n^{0} 75 / 2008$ consagra o diretor como "Uma espécie de líder hierárquico” (Lima, 2011, p. 57).

Neste sentido, foram criadas condições, do ponto de vista formal, para uma alteração profunda nas relações de poder no interior da escola, na medida em que se procura que "em cada escola exista um rosto, um primeiro responsável", no sentido de "reforçar a liderança da escola e de conferir maior eficácia, mas também mais responsabilidade ao director (Decreto-Lei ${ }^{\circ}$ 75/2008, 22 de abril). No passado, nomeadamente no âmbito da gestão democrática, as relações de poder caracterizavamse por tempos e espaços em que as decisões, ainda que apenas em matérias de gestão-execução, pautavam-se pela possibilidade de manifestação de interesses diversificados, pela liberdade de expressão e abertas à participação, por lógicas colegiais, especificamente no caso dos professores.

Face ao exposto, parece existir um leque de possibilidades de lideranças emergentes, assumidas pelos atores ora como mais individuais, ora como mais estratégicas ou, ainda, como mais democráticas. Constitui-se um desafio questionarmos se no plano da ação se reproduz o perfil do líder unipessoal, assacando a si os poderes e competências previstos na legislação ou se os atores escolares resistem a esta figura, demonstrando capacidade de produzirem orientações próprias no sentido da democratização da gestão da escola, na qual há uma partilha de poderes e competências, ainda a que num registo não formal e informal.

Por outro lado, no modelo em causa, com os argumentos de "reforçar a participação, de "abertura da escola ao exterior" e de consagrar "não apenas os direitos de participação dos agentes do processo educativos", instituiu-se um "orgão de direção estratégia" (DecretoLei $n^{0} 75 / 2008$, de 22 de abril). A este órgão designado de conselho geral "confia-se a capacidade de eleger e distituir o diretor, que por conseguinte lhe tem de prestar contas" (ibídem).

Contudo, não podemos deixar de questionar esta função estratégica do conselho geral no quadro de um modelo de administração do sistema educativo que se caracteriza como centralizado desconcentrado (cf. Formosinho, 1986), bem como a inexistência de autonomia para as escolas públicas portuguesas.

Face a este cenário, apresentamos um segundo desafio que consiste em conhecer e problematizar o lugar que ocupa cada uma destas figuras, o conselho geral e o diretor, no interior da escola. Podemos interrogar se não haverá uma tendência para uma desvalorização do órgão colegial e protagonismo do diretor. De modo específico, podemos interrogar que questões pode o conselho geral discutir no âmbito da definição da política da escola/agrupamento, se esta não é detentora de autonomia e, ainda, face à possibilidade de o diretor influenciar o funcionamento deste órgão, uma vez que possui um leque bastante amplo de competências no interior da escola.

De modo a refletirmos sobre as questões anteriormente mencionadas, mobilizamos dados de um estudo de caso, de uma escola do ensino secundário, situada no Norte do país, apresentados nos pontos que se seguem. Este estudo insere-se numa investigação mais ampla desenvolvida por um grupo de investigadores do Centro de Investigação em Educação, Instituto de Educação, Universidade do Minho, sobre A governação e gestão das escolas públicas: o(a) diretor(a) em ação, sendo um dos seus eixos de análise a introdução da Nova Gestão Pública (cf. Clarke \& Newman, 1997, Ball, 2005)

\section{Notas metodológicas}

A metodologia de suporte ao estudo situa-se num paradigma de investigação naturalista, cujo método de estudo de caso se socorre de técnicas tais como, o inquérito por questionário, o inquérito por entrevista aos atores escolares. Para o presente trabalho houve recurso a entrevistas semi-estruturadas, intencionalmente realizadas aos atores escolares (representante da autarquia do conselho geral, professor mais novo, professor mais velho da escola, coordenador de departamento e representante dos professores no conselho geral), sendo registadas sob a forma de áudio, após a obtenção das suas autorizações. Os participantes ficaram cientes de que os dados obtidos poderiam ser divulgados junto da comunidade académica, respeitando o carácter confidencial das identidades. O trabalho de campo decorreu no período compreendido entre julho de 2014 a dezembro de 2014 e possibilitou ainda a análise de documentos de cariz oficial.

\section{Breve caracterização da escola}

A escola onde se realizou o estudo de caso é um estabelecimento do ensino secundário criado no ano1979, situado no norte de Portugal. Trata-se de uma Escola sem contrato de autonomia e tem uma oferta formativa de $3^{\circ}$ Ciclo ( $7^{\circ}$ ano; $8^{\circ}$ ano; $9^{\circ}$ ano), com uma vertente de Cursos Científico-Humanísticos. A população da escola constitui-se em 180 professores, 55 funcionários e 1 psicóloga que têm por função apoiar 1498 alunos, repartidos por 8 turmas do $3^{\circ}$ ciclo do ensino básico diurno, 51 turmas do ensino secundário diurno (22 das quais de cursos profissionais) e 21 turmas do ensino noturno (6 dos cursos científico-humanísticos, 8 dos cursos tecnológicos e 7 dos Cursos de Educação e Formação de Adultos) (Regulamento Interno da Escola Secundária, 2013).

\section{O conselho geral: forma e substância em confronto}

Face ao discursos dos atores da escola em estudo parece que o principal atributo do conselho geral é a possibilidade de assegurar a participação na comunidade. Portanto, o carácter democrático deste órgão advém, na ótica dos participantes, da garantía da representatividade de diferentes categorías de atores no referido órgão. Regista-se, assim, que o conselho geral "é um órgão tipicamente democrático, tem os diferentes corpos da comunidade representados" (coordenador de 
departamento), "que integra elementos da comunidade, e isso é muito importante" (diretor), que sendo "um órgão onde estão representados, os professores, os alunos, os pais, a autarquia, outras entidades, podemos então ter opiniões diferentes" (presidente do conselho geral) e, ainda, tratar-se de um órgão possuidor de "uma grande virtude, é verdade, tenta fazer com que a comunidade participe na vida da escola"(representante da autarquia no conselho geral).

Porém, esta potencialidade do órgão parece perder importância quando confrontada com as possibilidades reais de definição da política da escola, não coincidindo a forma com a substância. Desde logo, porque, de forma praticamente consensual entre os atores, este órgão é desvalorizado pelo ministério da educação, como podemos confirmar nestas palavras:

"se alguém desse ouvidos ao conselho geral, quando eu digo alguém, é mais acima (...), se o conselho geral tomasse uma posição e depois o ministério, mas afinal cada um pode tomar as decisões que entender, porque as ordem vêm de cima" (professora mais antiga).

Neste cenário, o diretor chega mesmo a interrogar: " $\mathrm{O}$ que adianta termos uma gestão democrática se não somos ouvidos pelo ministério?" (diretor) e, nesse mesmo sentido, "o que interessa o modelo de gestão, se não há autonomia, o que interessa?" (presidente do conselho geral).

No plano interno da escola, a relação entre diretor e presidente do conselho geral define-se para alguns como "cordial, com diálogo do ponto de vista institucional "(coordenador de departamento) e o conselho geral pode ser considerado como um "órgão colaborativo, de opinião" (presidente do conselho geral). Também a relação é considerada de muito próxima para um dos entrevistados:

"(...) o diretor e o conselho geral sempre tiveram uma relação de cooperação, na altura de tomada de posse, por exemplo, veio o diretor e veio o presidente do conselho geral, (...) há uma relação de proximidade com o diretor" (presidente da associação de estudantes).

Não obstante a boa relação entre os dois órgãos, é evidenciada uma tendência de sobreposição do diretor face ao conselho geral e, por sua vez, uma subordinação deste último face ao diretor, na medida em que: i) "a agenda da reunião é conversada entre o presidente do conselho geral e o diretor e também porque o diretor informa o presidente do conselho geral das suas decisões" (presidente do conselho geral); ii) por vezes é a própria direção a incitar o surgimento das referidas listas (cf, entrevista do diretor). Neste cenário, não será de admirar que quando interrogados os atores sobre onde se localiza o poder no interior da escola, uma parte significativa tenha referido que é no órgão de gestão, ou se seja no diretor, até porque

“(...) é o director que tem de decidir e é o director quem se responsabiliza pelas suas decisões, não é o conselho geral (...) o conselho geral não está todos os días na escola (...) portanto, é o director, todo o resto é conversa, penso eu, mas isto é o que me diz a experiência" (representante da autarquía no conselho geral).

Apesar de internamente o conselho geral apresentar um papel diminuto, devido em grande parte ao protagonismo dado pela lei ao director, para alguns atores parece que o poder do conselho geral aumenta quando se trata de reivindicar, fora dos muros da Escola, maior autonomía para esta organização:

“(...) com o conselho geral a comunidade passou a ter a visão de como a escola é limitada, que não tem autonomia. É bom que tenham essa visão porque sensibilizando a comunidade eles podem em diferentes instâncias participarem e dizerem que a escola tem de ter uma maior margem de autonomia" (diretor).

\section{O poder formal do diretor e a mudança na continuidade}

A concentração de poderes no diretor consiste noutra mudança atribuída à publicação do Decreto-Lei $\mathrm{n}^{\mathrm{o}}$ $75 / 2008$, como referimos anteriormente. Contudo, os atores entrevistados fazem uma dissociação entre a lei e as práticas naquela escola em concreto.

Quanto à lei, os atores claramente identificam nesta a concentração de poderes na figura do diretor. Assim, refere uma das entrevistadas que é "Na lei, onde se decide é ali mesmo no gabinete do diretor" (professora mais antiga). Esta ideia é também reforçada por um dos representantes dos professores no conselho geral e por um coordenador de departamento ao compararem o atual modelo com o anterior, nomeadamente, no que diz respeito à existência de assessorias e ao funcionamento colegial, respetivamente:

"Eu, às vezes, questiono-me sobre isto, tendo em conta que o poder está muito centrado no diretor, enquanto no anterior modelo havia um conselho e acho que havia uma delegação de poderes pelas várias assessorias, agora não, está tudo muito concentrado no diretor. (...). Eu acho que o órgão de decisão máxima acaba por ser a direção" (professor do conselho geral).

“(..) se lermos a legislação de uma forma muito restritiva nem tudo pode ser delegado, o que é que acontece vamos concentrar tudo no diretor, criando uma situação terrível. (...) porque nem tudo é delegável e há muita coisa que para uma organização viva, não pode parar num organismo vivo, e por isso é mau que esteja tão concentrado, funcionava e sempre funcionamos muito bem com os órgãos colegiais, eu gostei muito do modelo com o conselho diretivo" (coordenador de departamento)

De entre os poderes concentrados na figura do director, há referências concretas à nomeação dos coordenadores de departamento, ainda que os entrevistados se mostrem em desacordo com a mesma:

"Claro que o diretor tem o poder muito centrado nele inclusive em determinadas situações permite que ele 
designe ou nomeie um representante para certas estruturas da escola. Por exemplo, o de coordenador de departamento e de outras estruturas. É claro que isso já não é muito democrático, acho que dentro de um departamento o seu coordenador deveria ser escolhido pelos membros desse departamento" (professor mais novo).

Esta preocupação dos professores, com a nomeação dos coordenadores de departamento, justifica-se porque são sobretudo estes que "correm o risco de ficar reféns do director, sem órgãos próprios e autónomos, sem intermediação e tipo colegial, no quadro de uma estrutura interna extremamente centralizada na figura do director" (Lima, 2011, p. 58).

Porém, reconhece-se que ao nível do domínio da ação organizacional da escola investigada parece existir uma desvinculação da lei, quando os atores referem que não houve grandes mudanças, justamente porque a pessoa que ocupa o cargo de diretor é a mesma que ocupava o cargo de presidente do conselho executivo, mantendo-se, na perspetiva dos entrevistados, uma ação democrática, como a que existia anteriormente. A este propósito, um dos entrevistados refere que o diretor procura "ser o mais democrático possível", nomeadamente pela razão de solicitar a opinião de outros atores:

"Não, não mudou, só mesmo esses pormenores, não é? O não podermos ser verdadeiramente democráticos ..., porque de facto ele tenta e aqui há esta tentativa de mesmo assim ser o mais democrático possível (...)" (professora mais antiga).

$\mathrm{Na}$ escola em questão, segundo os entrevistados "ele (diretor) gosta mais da gestão democrática e faz isso" (presidente do conselho geral) ou, então, "a práxis do diretor é que pode determinar esta distribuição de poder que eu acho que é vantajosa e acho que nesta escola a cultura tem sido nesse sentido (...) fala-se de alguém que já está aqui há 22 anos" (coordenador de departamento). Na perspetiva de outro entrevistado, não houve alterações significativas nas práticas deste diretor, o trabalho em equipa existia e continua a existir: "Muda só o nome, depois as coisas ... porque ele tem uma equipa que trabalha com ele, uma equipa que ele escolhe que já escolhera antes e que era eleita diretamente, (...). As pessoas que estão com ele agora eram pessoas que estavam antes" (representante da autarquia no conselho geral). Assim, o diretor partilha com os professores algum do seu poder de decisão e solicita opinião aos adjuntos da direção, como afirma uma das entrevistadas:

"O nosso diretor já com muitas restrições dá oportunidades aos grupos (...) o nosso diretor não é assim uma figura... e é por isso que ele se aguenta aqui há tantos anos, é uma pessoa aberta e, portanto, não toma essas decisões. (...) eu acho que não pede a opinião para dizer 'estou acompanhado ou estou sozinho', ele pede genuinamente, é alguém com espírito democrático, felizmente ainda bastante dentro da cabeça" (professora mais antiga).
A tomada de decisão por parte do diretor tem subjacente a opinião de outros atores: "ele (diretor) tem a opinião dos outros no dia a dia, tem do subdiretor, tem de uma série de assessores e, obviamente, quando toma uma decisão ele já ouviu" (professor do conselho geral).

A passagem serena da gestão colegial para a unipessoal teve como principal razão a continuidade da liderança da pessoa que ocupa o cargo de gestão:

“(...) não mudou muito, são as mesmas pessoas, não se muda a mentalidade porque a lei mudou" (presidente do conselho geral);

“(...) como nós temos vindo a atravessar a gestão com a mesma pessoa; ou seja, com o diretor não notamos muito essa diferença (professor do conselho geral);

“(...) não sentimos grandes mudanças porque o sr. diretor ou antigo executivo sempre teve aquelas linhas orientadoras e, portanto, não fugiu muito do que era e do que é" (funcionário do conselho geral).

Afigura-se, deste modo, a sobreposição da pessoa ao modelo como parecem confirmar alguns dos atores "o importante não é tanto o modelo, mas antes a pessoa" (coordenador de departamento) e o que "conta mais é a postura das pessoas que lideram” (diretor).

Apesar da construção ou aproveitamento de margens autonomía, em benefício de uma gestão com características democráticas, o que é facto é que os atores identificam condicionantes nessa forma de funcionamento, designadamente pela 'carga de responsabilidade' atribuída ao diretor.

\section{Considerações finais}

O novo modelo de gestão unipessoal que contempla a figura do diretor, surge legitimado pela necessidade de cada escola pública ter um responsável, a quem o ministério pode assacar responsabilidade várias. Apesar da recente mudança legislativa (Decreto-Lei no 75/2008), o presente estudo de caso permitiu conhecer e problematizar a relação entre o diretor e o conselho geral e os sentidos de colegialidade na gestão.

Nesse sentido, os atores da escola em causa identificam mudanças na legislação direcionadas para estes eixos, embora nas suas óticas tais alterações tiveram pouco impacto na escola. Duas razões contribuem para esta situação, a primeira deve-se às mudanças de cosmética, designadamente para o caso do conselho geral, pelo seu papel diminuto quando confrontado com as possibilidades reais de definição da política da escola, não coincidindo a forma com a substância. Neste caso os atores parecem percecionar de forma praticamente consensual que este órgão é desvalorizado pelo Ministério da Educação. A segunda razão deve-se à continuidade dos dirigentes escolares, de um modelo para outro, desvalorizando-se a natureza colegial ou unipessoal do órgão de gestão. Para os atores escolares a passagem serena da gestão colegial para a unipessoal teve como principal fundamento a continuidade da liderança da pessoa que ocupa o cargo de gestão e, inclusive, de sua equipa. 
Os dados agora discutidos permitem-nos identificar a importância de uma reflexão aprofundada sobre os sentidos da democracia em contexto escolar a que a formação de professores, inicial ou contínua, não pode estar alheia.

\section{Referências}

Ball, S. (2005), Profissionalismo, gerencialismo e performatividade. Cadernos de Pesquisa, 35(126), pp.539-564.

Clarke,J. \& Newman, J. (1997), The managerial state: power, politics and ideology in the remaking of social welfare. London: Sage Publications.

Formosinho, J. (1986), A regionalização do sistema de ensino, Cadernos Municipais, Revista de Ação Regional e Local, $\mathrm{n}^{\circ}$ 3839, Dezembro. pp. 63-67

Lima, L. (2011). Diretor de escola: subordinação e poder. In António Neto-Mendes, Jorge A. Costa, e Alexandre Ventura (orgs.), A Emergência do Director da Escola, Questões Políticas e Organizacionais, Atas do VI Simpósio sobre organização e gestão escolar (pp.4763). Aveiro: Universidade de Aveiro.

Lima, L. (2007). A deliberação democrática nas escolas: os procedimentos gerenciais e as decisões políticas. In $\mathrm{M}^{\mathrm{a}}$ Fátima Chorão Sanches, Feliciano Veiga, Florbela de Sousa e Joaquim Pintasilgo, Cidadania e Liderança Escolar (pp.39-55). Porto: Porto Editora.

Martins, F. (2011). Tempos de mudanças na administração da escola pública em Portugal: a (re)emergência do diretor e a concentração de poderes. In Jorge A. Costa, e Alexandre Ventura (orgs.), A Emergência do Director da Escola, Questões Políticas e Organizacionais, Atas do VI Simpósio sobre organização e gestão escolar (pp.91-104). Aveiro: Universidade de Aveiro.

Martins, F. (2009). Gerencialismo e quase-mercado educacional: a acção organizacional numa escola secundária em época de transição. Tese de Doutoramento em Educação, especialização em Organização e Administração Escolar. Braga: Universidade do Minho.

\section{Agradecimentos}

This work is funded by CIEd - Research Centre on Education, projects UID/CED/1661/2013 and UID/CED/1661/2016, Institute of Education, University of Minho, through national funds of FCT/MCTES-PT

\section{Legislação}

Decreto-Lei no 75/2008, de 22 de abril, Regime de Autonomia, Administração e Gestão dos Estabelecimentos Públicos da Educação Pré -Escolar e dos Ensinos Básico e Secundário. 